\title{
Survivin promoter rs9904341 polymorphism is associated with tumor stage and grade in patients with bladder cancer
}

\author{
Zhon-Min Huang $^{1^{*}}$, Yi-Te Chiang ${ }^{2^{*}}$, Min-Che Tung ${ }^{1^{*}}$, Chia-Chang $\mathrm{Wu}^{2}$, Kuan-Chou Chen ${ }^{2}$, \\ Ming-Te Huang ${ }^{3}$, Yuan-Hung Wang ${ }^{4,5 \#}$, Cheng-Huang Shen ${ }^{6 \#}$ \\ ${ }^{1}$ Department of Urology, Tung's Taichung MetroHarbor Hospital, Taichung County, Taiwan \\ ${ }^{2}$ Department of Urology, Shuang Ho Hospital, Taipei Medical University, New Taipei City, Taiwan \\ ${ }^{3}$ Division of General Surgery, Department of Surgery, Shuang Ho Hospital, Taipei Medical University, Taipei, Taiwan \\ ${ }^{4}$ Division of General Surgery, Department of Urology, Shuang Ho Hospital, Taipei Medical University, New Taipei City, Taiwan \\ ${ }^{5}$ Graduate Institute of Clinical Medicine, College of Medicine, Taipei Medical University, Taipei, Taiwan \\ ${ }^{6}$ Department of Urology, Chia-Yi Christian Hospital, Chiayi City, Taiwan \\ Email: ${ }^{\#}$ 5508091002@tmu.edu.tw, ${ }^{*}$ b712@cych.org.tw
}

Received 15 October 2012; revised 17 November 2012; accepted 25 December 2012

\begin{abstract}
Survivin is an inhibitor of apoptosis protein and also plays a important role in the development of several malignancies. To investigate the association between survivin promoter -31 G/C (rs9904341) polymorphism and bladder cancer (BC) risk. A total of 200 pathologically confirmed $\mathrm{BC}$ cases and 200 unrelated cancer-free controls were recruited in Chiayi Christian Hospital from August 2002 to May 2009. Polymerase chain reaction-restriction fragment length polymorphism (PCR-RFLP) method was used to determine the $-31 \mathrm{G} / \mathrm{C}$ polymorphism at survivin promoter region. There was a significant difference in the frequency distribution of survivin promoter -31 $\mathrm{G} / \mathrm{C}$ polymorphism in $\mathrm{BC}$ cases as compared to controls. Among $\mathrm{BC}$ cases, individuals with the $\mathrm{C} / \mathrm{C}$ genotype of survivin promoter have a significantly higher prevalence of invasive (T2-T4) or high-grade (G2-G3) tumors as compared to those who carried the $\mathbf{G} / \mathbf{G}$ genotype. In conclusion, our findings suggest that the survivin promoter $-31 \mathrm{G} / \mathrm{C}$ polymorphism was not only associated with clinical stage and pathological grade but also involved in the development of bladder cancer.
\end{abstract}

Keywords: Survivin; Bladder Cancer; Polymorphism; Apoptosis

\section{INTRODUCTION}

Apoptosis usually involved in carcinogenesis through prolonging cell survival, promoting the accumulation of mutations and enhancing resistance to therapy [1]. Survi-

\footnotetext{
*These authors contributed equally to this work.

\#Corresponding authors.
}

vin is an inhibitor of apoptosis protein and possesses anti-apoptosis effective pathways through the influences on initiator (caspase-9) and effectors (caspase-3) [2]. Survivin is expressed in the embryonic tissues and in various human malignancies, but in normal, well-differentiated adult tissues it is almost undetectable [3]. Therefore, survivin is considered to play an critical role in carcinogenesis, and associated with poor prognosis in various cancers [4].

Bladder cancer is the second most common malignancy of the genitourinary tract and it is the eighth most commonly malignancy among men in Taiwan [5]. Previous studies have reported that increased survivin expression was associated with various cancers including bladder, colorectal, lung and oral [6-10]. A previous study reported that survivin was detected in urine samples from patients with new or recurrent bladder cancer but not found from healthy volunteers [11]. Another study observed that higher levels of survivin in urine samples were associated an increased risk of bladder cancer and higher grade of tumor, but not with advanced stage [12]. Survivn could be detected by the immunohistochemical analysis in a high proportion of cases of urothelial carcinoma [13]. Another study reported that survivin over-expressed in tumor cells but not in normal urothelium cell [14]. However, the clinical application of survivin and its relation with tumor stage and grade of bladder cancer still require more studies.

The gene coding for survivin is located at chromosome 17q25 [15]. A feature of survivin promoter is the existence of a cell cycle-dependent element and a cell cycle homology region [3]. Deletion of this promoter region may lead to the lack of cell cycle-dependent expression in HeLa cells [16]. We proposed that polymorphisms in survivin promoter region may modulate 
gene expression or enzyme activity, thereby affecting the individual susceptibility to bladder cancer. Therefore, we conducted a case-control study to investigate the potential effect of a survivin promoter $-31 \mathrm{G} / \mathrm{C}$ (rs9904341) polymorphism on bladder cancer.

\section{MATERIALS AND METHODS}

\subsection{Study Subjects}

The present study consisted of a total of 200 bladder cancer $(\mathrm{BC})$ cases, diagnosed at the Department of Urology of the Chiayi Christian Hospital between August 2002 and May 2009. Pathological confirmation of $\mathrm{BC}$ was performed by regular urological practice including endoscopic biopsy and surgical resection of urinary tract tumors. Staging and grading of tumors was determined by the criteria of the tumor-node-metastasis (TNM) staging system and the WHO International Society of Urological Pathology $[17,18]$. Clinical stage was classified into two subgroups, including superficial $(\leq \mathrm{T} 1)$ and invasive (T2-T4). Pathological grade was recorded as G1, G2 and G3. A total of 200 cancer-free controls, frequency-matched with $\mathrm{BC}$ cases on gender and age ( \pm 5 years), were recruited from those who admitted to the same hospitals for a health examination and had no urological neoplastic diseases or malignancies. All participants given a detailed description of this study and signed informed consents. This study was approved by the Ethics Committee of Chiayi Christian Hospital.

\subsection{Genotyping of Survivin Promoter -31 G/C Polymorphism}

A venous blood sample $(6 \mathrm{ml}-8 \mathrm{ml})$ was drawn into an EDTA vial for each participant. Genomic DNA was extracted from peripheral lymphocytes by proteinase $\mathrm{K}$ digestion and phenol/chloroform method. A polymerase chain reaction-restriction fragment length polymorphism (PCR-RFLP) was used to determine survivin promoter $-31 \mathrm{G} / \mathrm{C}$ polymorphism. PCR reaction was performed in a volume of $50 \mu$ containing $50 \mathrm{ng}$ genomic DNA, $5 \mu \mathrm{l}$ of $10 \times$ polymerase buffer, $0.1 \mathrm{mM}$ dNTPs, $20 \mathrm{pmol} / 1$ of forward primer (5'-GTTCTTTGAAAGCAGTCGAG-3') and reverse primer

(5'-GCCAGTT CTTGAATGTAGAG-3'), and $1.5 \mathrm{U}$ of Taq polymerase (Invitrogen, San Diego, Ca). The PCR program was started with an initial denaturation at $95^{\circ} \mathrm{C}$ for $5 \mathrm{~min}$, followed by 35 cycles of denaturation at $95^{\circ} \mathrm{C}$ for $30 \mathrm{~s}$, annealing at $58^{\circ} \mathrm{C}$ for $90 \mathrm{~s}$, extension at $72^{\circ} \mathrm{C}$ for $90 \mathrm{~s}$, and completed with a final elongation step at $72^{\circ} \mathrm{C}$ for $10 \mathrm{~min}$. The 341-bp PCR product was digested with the restriction enzyme EcoO109I (New England Biolabs) at $37^{\circ} \mathrm{C}$ for overnight. The 236-bp and 105 -bp fragments for the $\mathrm{G}$ allele, whereas the $\mathrm{C}$ allele is not digested.

\subsection{Statistical Analysis}

The $X^{2}$ test was used to test Hardy-Weinberg equilibrium (HWE) by comparing the observed genotype frequencies with the expected frequencies among controls. The correlation between survivin promoter $-31 \mathrm{G} / \mathrm{C}$ polymorphism of and clinical stage or pathological grade of BC was examined by the $X^{2}$ test. SAS version 6.12 (SAS Institute, Cary, NC) was used for all analyses with twotailed probabilities. The differences between compared groups were considered to be significant if the p-values were less than 0.05 .

\section{RESULTS}

\subsection{The Distribution of Basic Characteristics}

The distribution of basic characteristics for $\mathrm{BC}$ cases and cancer-free controls was shown in Table 1. The mean age \pm standard deviation (SD) was $63.8 \pm 8.2$ and $63.0 \pm$ 8.3 years for $\mathrm{BC}$ cases and controls, respectively. There were no significant differences in age and gender between the $\mathrm{BC}$ case and cancer-free controls. The prevalence of cigarette smoking is higher in $\mathrm{BC}$ cases $(51.5 \%)$ than in cancer-free controls $(45.0 \%)$. Among $\mathrm{BC}$ cases, $64 \%$ were invasive (T2-T4) and $77 \%$ were high-grade (G2-G3) tumors.

\subsection{The Distribution of Survivin Promoter -31 C/G Polymorphism in BC Cases and Controls}

The observed genotype frequencies of survivin promoter $-31 \mathrm{G} / \mathrm{C}$ polymorphism among cancer-free controls was in $\operatorname{HWE}(\mathrm{p}=0.981)$. The genotype distribution of survivin promoter $-31 \mathrm{G} / \mathrm{C}$ polymorphism was shown in Table 2. The prevalence of $\mathrm{C} / \mathrm{C}$ and $\mathrm{C} / \mathrm{G}$ genotypes of survivin gene was higher in $\mathrm{BC}$ cases than in cancer-free controls and a statistically significant difference in the genotype distribution between $\mathrm{BC}$ cases and cancer-free controls was observed $\left(X^{2}=10.6 ; \mathrm{p}=0.005\right)$.

\subsection{The Association between Survivin Promoter -31 C/G Polymorphism and Clinical Stage and Pathological Grade}

The relation between survivin promoter $-31 \mathrm{G} / \mathrm{C}$ polymorphism and clinical stage and pathological grade of $\mathrm{BC}$ cases was shown in Table 3. There was a significant association between survivin promoter $-31 \mathrm{G} / \mathrm{C}$ polymorphism and clinical stage of $\mathrm{BC}$ cases $\left(X^{2}=7.8 ; \mathrm{p}=\right.$ 0.02 ). In addition, a significant association between the survivin promoter $-31 \mathrm{G} / \mathrm{C}$ polymorphism and pathological grade of $\mathrm{BC}$ cases was also found in the present study $\left(X^{2}=13.3 ; \mathrm{p}=0.009\right)$. 
Table 1. Distribution of characteristics for BC cases and controls.

\begin{tabular}{|c|c|c|}
\hline \multirow{2}{*}{ Characteristic } & $\mathrm{BC}$ cases & Controls \\
\hline & n $(\%)$ & n $(\%)$ \\
\hline \multicolumn{3}{|l|}{ Age (years) } \\
\hline$<55$ & $38(19.0)$ & $24(12.0)$ \\
\hline $55-69$ & $106(53.0)$ & $124(62.0)$ \\
\hline$\geq 70$ & $56(28.0)$ & $52(26.0)$ \\
\hline \multicolumn{3}{|l|}{ Gender } \\
\hline Female & $60(30.0)$ & $60(30.0)$ \\
\hline Male & $140(70.0)$ & $140(70.0)$ \\
\hline \multicolumn{3}{|l|}{ Cigarette smoking } \\
\hline Never & 97 (48.5) & $110(55.0)$ \\
\hline Ever & $103(51.5)$ & $90(45.0)$ \\
\hline \multicolumn{3}{|l|}{ Clinical stage } \\
\hline Superficial $(\leq \mathrm{T} 1)$ & $128(64.0)$ & - \\
\hline Invasive (T2 - T4) & $72(36.0)$ & - \\
\hline \multicolumn{3}{|l|}{ Pathological grade } \\
\hline Grade 1 (G1) & $46(23.0)$ & - \\
\hline Grade 2 (G2) & $76(38.0)$ & - \\
\hline Grade 3 (G3) & $78(39.0)$ & - \\
\hline
\end{tabular}

Table 2. Distribution of Survivin $-31 \mathrm{G} / \mathrm{C}$ polymorphism in BC cases and controls.

\begin{tabular}{cccc}
\hline \multirow{2}{*}{$\begin{array}{c}\text { Survivin }-31 \mathrm{G} / \mathrm{C} \\
\text { polymorphism }\end{array}$} & $\mathrm{BC}$ cases & Controls & \multirow{2}{*}{$X^{2}$ (p-value) } \\
\cline { 2 - 3 } & $\mathrm{n}(\%)$ & $\mathrm{n}(\%)$ & \\
\hline $\mathrm{C} / \mathrm{C}$ & $66(33.0)$ & $59(29.5)$ & \\
$\mathrm{C} / \mathrm{G}$ & $102(51.0)$ & $82(41.0)$ & $10.6(0.005)$ \\
$\mathrm{G} / \mathrm{G}$ & $32(16.0)$ & $59(29.5)$ & \\
\hline
\end{tabular}

Table 3. Survivin $-31 \mathrm{G} / \mathrm{C}$ polymorphism distribution according to clinical stage and pathological grade.

\begin{tabular}{ccccc}
\hline \multirow{2}{*}{$\begin{array}{c}\text { Clinical } \\
\text { parameter }\end{array}$} & \multicolumn{3}{c}{ Survivin $-31 \mathrm{G} / \mathrm{C}$ polymorphism } & \multirow{2}{*}{$X^{2}$ (p-value) } \\
\cline { 2 - 5 } & $\mathrm{C} / \mathrm{C}$ & $\mathrm{C} / \mathrm{G}$ & $\mathrm{G} / \mathrm{G}$ & \\
\hline Clinical stage & & & & \\
Superficial ( $\leq \mathrm{T} 1)$ & $34(51.5)$ & $69(67.6)$ & $25(78.1)$ & $7.8(0.02)$ \\
Invasive (T2 - T4) & $32(48.5)$ & $33(32.4)$ & $7(21.9)$ & \\
Pathological grade & & & & \\
Grade 1 (G1) & $13(19.7)$ & $25(24.5)$ & $8(25.0)$ \\
Grade 2 (G2) & $28(42.4)$ & $29(28.4)$ & $19(59.4)$ & $13.3(0.009)$ \\
Grade 3 (G3) & $25(37.9)$ & $48(47.1)$ & $5(15.6)$ \\
\hline
\end{tabular}

\section{DISCUSSION}

Bladder cancer is a multi-factorial malignancy and several susceptible genes have been proposed to be associated with the development of bladder cancer. Recently, several studies reported that there was a close relationship between apoptosis and various malignancies $[1,19$, 20]. Polymorphisms of survivin gene may modulate the gene expression and enzyme activity of survivin in various malignancies [21-25]. In the present study, we investigate the association between survivin promoter $-31 \mathrm{G} / \mathrm{C}$ (rs9904341) polymorphism and bladder cancer.

A major finding of our study was a significant association between survivin promoter $-31 \mathrm{G} / \mathrm{C}$ polymorphism and bladder caner. This observation was consistent with previous studies regarding the $-31 \mathrm{G} / \mathrm{C}$ polymorphism of survivin promoter. Jang et al. shown that the genotype frequencies for $\mathrm{C} / \mathrm{C}$ and $\mathrm{C} / \mathrm{G}$ were $31.6 \%$ and $44.5 \%$ in lung cancer patients, and $25.3 \%$ and $50.3 \%$ in controls, respectively [22]. They also found that subjects carrying at least one $-31 \mathrm{G}$ allele have a significantly decreased lung cancer risk as compared with those with the $-31 \mathrm{C} / \mathrm{C}$ genotype. Cheng et al. reported that the genotype frequencies for $\mathrm{C} / \mathrm{C}$ and $\mathrm{C} / \mathrm{G}$ genotypes were $39.6 \%$ and $39.6 \%$ in gastric cancer patients, and $11.9 \%$ and $41.8 \%$ in controls, respectively, but no different survivin expression was found in gastric cancer tissues stratified by genotypes [24].

The effect of survivin promoter $-31 \mathrm{G} / \mathrm{C}$ polymorphism was tested by a luciferase reporter expression assay, the $-31 \mathrm{G}$ allele significantly decreased promoter activity as compared with the $-31 \mathrm{C}$ allele in Hela cells [22]. In contrast, $\mathrm{Xu}$ et al. reported that the $-31 \mathrm{G} / \mathrm{C}$ polymorphism might enhance the survivin expression at both the mRNA and protein levels [25]. Therefore, more detailed studies should be needed to elucidate the effects of the $-31 \mathrm{G} / \mathrm{C}$ polymorphism on survivin expression. In addition, survivin was identified as a candidate gene suppressed by the wild-type p53 [26]. Because the deficiency of the wild-type p53 is the most genetic disorders in carcinogenesis, it implied a pathway to account for overexpression of survivin in various cancers.

In the present study, the prevalence of invasive (T2-T4) and high-grade (G2-G3) BC cases was higher in subjects carrying the $\mathrm{C} / \mathrm{C}$ genotype than in those with the $\mathrm{G} / \mathrm{G}$ genotype. Previous studies reported that the expression of survivin was significantly increased in patients with a higher tumor grade of urinary tract malignancies [27-32]. Swana et al. shown that bladder cancer patients with higher survivin expression have a shorter time to recurrence [13]. These findings indicated that the promoter $-31 \mathrm{G} / \mathrm{C}$ polymorphism may result in the overexpression of survivin. The deficient apoptosis pathway will lead to the accumulation of mutated or poor-differentiated cells 
and accelerate tumor progression [1]. Therefore, the -31 $\mathrm{G} / \mathrm{C}$ polymorphism of survivin promoter region may involve in tumor initiation, promotion and progression.

In conclusion, our findings suggest that the survivin promoter $-31 \mathrm{G} / \mathrm{C}$ (rs9904341) polymorphism was not only associated with the risk of bladder cancer but also related with invasive and high-grade tumors. Moreover, genetic polymorphisms usually vary in various populations, further studies with larger sample size are required to clarify the relationship between genotype and phenotype in different ethnic populations.

\section{ACKNOWLEDGEMENTS}

This work was supported by the grant from the Chiayi Christian Hospital (R95-4).

\section{REFERENCES}

[1] Melet, A., et al. (2008) Apoptotic pathways in tumor progression and therapy. Advances in Experimental Medicine and Biology, 615, 47-79. doi:10.1007/978-1-4020-6554-5 4

[2] Reed, J.C., et al. (2001) The Survivin saga goes in vivo. The Journal of Clinical Investigation, 108, 965-969. doi:10.1172/JCI14123

[3] Sah, N.K., et al. (2006) Structural, functional and therapeutic biology of survivin. Cancer Letters, 244, 164-171. doi:10.1016/j.canlet.2006.03.007

[4] Duffy, M.J., et al. (2007) Survivin: A promising tumor biomarker. Cancer Letters, 249, 49-60. doi:10.1016/i.canlet.2006.12.020

[5] Shen, C.H., et al. (2007) Inducible nitric oxide synthase promoter polymorphism, cigarette smoking, and urothelial carcinoma risk. Urology, 69, 1001-1006. doi:10.1016/j.urology.2007.02.028

[6] Margulis, V., et al. (2008) Survivin: A promising biomarker for detection and prognosis of bladder cancer. World Journal of Urology, 26, 59-65. doi:10.1007/s00345-007-0219-y

[7] Karam, J.A., et al. (2007) Survivin expression in patients with non-muscle-invasive urothelial cell carcinoma of the bladder. Urology, 70, 482-486.

doi:10.1016/j.urology.2007.05.009

[8] Ponnelle, T., et al. (2005) Cellular localisation of survivin: Impact on the prognosis in colorectal cancer. Journal of Cancer Research and Clinical Oncology, 131, 504-510. doi:10.1007/s00432-005-0682-z

[9] Ulukus, E.C., et al. (2007) Survivin expression in nonsmall-cell lung carcinomas: Correlation with apoptosis and other apoptosis-related proteins, clinicopathologic prognostic factors and prognosis. Applied Immunohistochemistry \& Molecular Morphology, 15, 31-37. doi:10.1097/01.pai.0000201808.35931.78

[10] Lin, C.Y., et al. (2005) Survivin expression predicts poorer prognosis in patients with areca quid chewing-related oral squamous cell carcinoma in Taiwan. Oral On- cology, 41, 645-654. doi:10.1016/j.oraloncology.2005.02.009

[11] Smith, S.D., et al. (2001) Urine detection of survivin and diagnosis of bladder cancer. Journal of the American Medical Association, 285, 324-328. doi:10.1001/jama.285.3.324

[12] Shariat, S.F., et al. (2004) Urine detection of survivin is a sensitive marker for the noninvasive diagnosis of bladder cancer. Journal of Urology, 171, 626-630. doi:10.1097/01.ju.0000107826.78479.90

[13] Swana, H.S., et al. (1999) Tumor content of the antiapoptosis molecule survivin and recurrence of bladder cancer. The New England Journal of Medicine, 341, 452453. doi:10.1056/NEJM199908053410614

[14] Ku, J.H., et al. (2004) Expression of survivin, a novel inhibitor of apoptosis, in superficial transitional cell carcinoma of the bladder. Journal of Urology, 171, 631-635. doi:10.1097/01.ju.0000106082.44786.3b

[15] Chiou, S.K., et al. (2003) Survivin-An anti-apoptosis protein: Its biological roles and implications for cancer and beyond. Medical Science Monitor, 9, PI25-P129.

[16] Li, F., et al. (1998) Control of apoptosis and mitotic spindle checkpoint by survivin. Nature, 396, 580-584. doi: $10.1038 / 25141$

[17] Gonul, I.I., et al. (2007) Comparison of 1998 WHO/ ISUP and 1973 WHO classifications for interobserver variability in grading of papillary urothelial neoplasms of the bladder. Pathological evaluation of 258 cases. Urology International, 78, 338-344. doi:10.1159/000100839

[18] Bircan, S., et al. (2004) Comparison of WHO 1973, WHO/ISUP 1998, WHO 1999 grade and combined scoring systems in evaluation of bladder carcinoma. Urology International, 73, 201-208. doi:10.1159/000080826

[19] Tan, T.T., et al. (2008) Therapeutic targeting of death pathways in cancer: Mechanisms for activating cell death in cancer cells. Advances in Experimental Medicine and Biology, 615, 81-104. doi:10.1007/978-1-4020-6554-5 5

[20] Coppola, J.M., et al. (2008) Noninvasive imaging of apoptosis and its application in cancer therapeutics. Clinical Cancer Research, 14, 2492-2501. doi:10.1158/1078-0432

[21] Borbély, A.A., et al. (2007) Survivin promoter polymerphism and cervical carcinogenesis. Journal of Clinical Pathology, 60, 303-306. doi:10.1136/jcp.2006.037804

[22] Jang, J.S., et al. (2008) Polymorphisms in the survivin gene and the risk of lung cancer. Lung Cancer, 60, 31-39. doi:10.1016/j.lungcan.2007.09.008

[23] Wagner, M., et al. (2008) Epigenetic and genetic analysis of the survivin promoter in acute myeloid leukemia. Leukemia Research, 32, 1054-1060. doi:10.1016/j.leukres.2007.11.013

[24] Cheng, Z.J., et al. (2008) Correlation of $-31 \mathrm{G} / \mathrm{C}$ polymorphisms of survivin promoter to tumorigenesis of gastric carcinoma. Ai Zheng, 27, 258-263. doi:10.3760/cma.j.issn.1673-422X

[25] Xu, Y., et al. (2004) A mutation found in the promoter region of the human survivin gene is correlated to over- 
expression of survivin in cancer cells. DNA and Cell Biology, 23, 527-537. doi:10.1089/1044549041939278

[26] Hoffman, W.H., et al. (2002) Transcriptional repression of the anti-apoptotic survivin gene by wild type p53. The Journal of Biological Chemistry, 277, 3247-3257. doi:10.1074/ jbc.M106643200

[27] Pina-Cabral, L., et al. (2007) Detection of survivin mRNA in urine of patients with superficial urothelial cell carcinomas. Clinical and Translational Oncology, 9, 731-736. doi:10.1007/s12094-007-0130-4

[28] Schultz, I.J., et al. (2003) Survivin mRNA expression is elevated in malignant urothelial cell carcinomas and predicts time to recurrence. Anticancer Research, 23, 33273331. doi:10.1111/j.1365-2567.2008.02826.x

[29] Ohsawa, I., et al. (2004) Detection of urine survivin in 40 patients with bladder cancer. Journal of Nippon Medical School, 71, 379-383. doi:10.1272/jnms.71.379

[30] Wang, H., et al. (2004) The expression and significance of survivin mRNA in urinary bladder carcinomas. Journal of Cancer Research and Clinical Oncology, 130, 487490. doi:10.1007/s00432-004-0561-z

[31] Srivastava, K., et al. (2012) Survivin promoter -31G/C (rs9904341) polymorphism and cancer susceptibility: A meta-analysis. Molecular Biology Reports, 39, 1509-1516. doi:10.1007/s11033-011-0889-9

[32] Wang, X., et al. (2012) Association between survivin $-31 \mathrm{G}>\mathrm{C}$ promoter polymorphism and cancer risk: A meta-analysis. European Journal of Human Genetics, 20, 790-795. doi:10.1038/ejhg.2011.276 